\title{
Exploring the Fear of Travel: Study Revealing Into Tourists’ Minds
}

\author{
Korstanje Maximiliano \\ University of Palermo, Buenos Aires, Argentina \\ Geoffrey Skoll \\ Buffalo State College, Buffalo, USA
}

\begin{abstract}
Risk perception has received much attention in recent decades by tourism scholarship. The classical studies subject to quantitative-related methodologies point out that risk perception correlates with variables such as gender, income, class, nationality, and education. Beyond this paradigm, we have launched to discuss the potential contribution made by the attachment theory to unraveling the fascinating connection among fear, risk to travel, and mourning. Since the goals of qualitative research are not the necessarily representative sampling but the understanding of the relevant issues, we believe that these three cases are enough to identify the relevant issues. Our hypothesis is that travel reluctance comes from a self caused by a previous rapid loss of a love-object.
\end{abstract}

Keywords: risk, travels, fear, tourism, death, attachment

\section{Introduction}

Although millions of people travel from one to another point of the globe in quest of other landscapes, customs, and cultures, there are many others who are restrained due to psychological impediments. Leisure travel is for them a real nightmare. The tourism industry is based on the development of secure technologies to ensure the safety of travelers. Risk perception theory gained attention at the onset of a new century (Kozak, Crotts, \& Law, 2007; Korstanje, 2011a; 2011b). One of the main aspects of this research rests on the needs of understanding phobias, or extreme fear of travel, which often afflicts some potential travelers. Unfortunately, the tourism literature has not explored this matter. Some of the relevant questions are: Can travel agents have fear of travel? Who are travel avoiders? Is this a psychological attachment to figures of authority or a result of complacency? Is the experience a mechanism to diminish displaced anxieties?

Through this research note, we have collected three biographies using life history narratives. Two interviewees are males and the other is a female. They are 35-45 years old. They work in diverse sectors of the tourism industry. The role of the ethnographer was not revealed to participants. They have been selected using the snowball method from 45 interviews. Since the goals of qualitative research are not the necessarily representative sampling but the understanding of the relevant issues, we believe that these three cases are enough to identify the relevant issues. Our hypothesis is that travel reluctance comes from a self caused by a previous rapid loss of a love-object.

Korstanje Maximiliano, Dr. (Tourism), Department of Economics, University of Palermo. Email: Mkorst@palermo.edu. Geoffrey Skoll, Dr. (Anthropology), Department of Criminal Justice, Buffalo State College. 


\section{Conceptual Discussion}

The 21st century has brought changes that have shocked public opinion in an industrialized nation, such as virus outbreaks, natural disasters, and terrorist attacks. In view of that, the seminal studies of Roehl and Fesenmaier (1992) have been resurrected. Though tourism scholars had in the past devoted attention to the problem of risk (McCartney, 2008), the virulence of these new events affected international tourist destinations as never before. The communication of risk played a vital role in constructing plans to deter hazards that may hurt the industry (Hall, Timothy, \& Duval, 2003). Nevertheless, why some kinds of people are risk seekers while others are risk avoiders has not been addressed.

Psychology can contribute to explaining why some personalities or characters are sensible to risk while others are not. Most studies that explore the problem of risk today are based on the contributions of Plog (1973; 1991), who was financially supported by airline companies to develop a model to understand the adaptive behavior of diverse personalities to flying. Plog's model personality is structured according to three key factors: attachment to territory, anxiety, and impotence. Along this continuum, Plog's model establishes three personality types: allo-centric (oriented to know new customs and habits), mid-centric (the mixture of allo- and psycho-centric subtype), and psycho-centric which is based on a strong sense of ritualism and fear to the unknown). Plog was widely criticized since his hypothesized outcomes have not been replicated in other researches (Hoxter \& Lester, 1988). Nonetheless, his notion of anxiety associated with personality types represented a substantial advance in explaining diverse responses to risk. It is important to delineate the role of emotions not only in risk perception but also in the organization of personality. Tolerance of uncertainty is a correlative variable that explains the reason why some personalities become disorganized when they confront risk (Reisinger \& Mavondo, 2005). Other studies have criticized the meaning of risk, which corresponds with a cognitive perceptual unit tied to emotions. Qualitative methods could help explain the psychology of risk (Larsen, Bruna, \& Øgaardb, 2009; Korstanje, 2011a; 2011b). In particular, interesting findings may come from the application of the attachment theory.

Following the contributions of ethology, John Bowlby formulated a theory to describe the attachment of child with its mother. Starting from the premise that human beings develop reactions to contextual threat, Bowlby said that it is important to understand how the first years of life of the child will determine its future behavior. Children need to receive support from their care-takers (parents) to regulate their internal emotional life. The success of this process depends on their future ability to explore the environment. Based on the substantial clinical evidence he found, Bowlby explained that if the child experiences a loss of the attachment figure during the first months of life, its sense of autonomy will be seriously impaired. As a result of this, the child will be reluctant to explore unknown objects and environments. Effects of early stage socialization persist during adulthood (Bowlby, 1960).

\section{The Fear of Travelling}

Stories in this section are of real persons, whose names are changed to conceal their identities. We all feel fear at some moments of our lives, but this is nothing to what Charles reported feeling when flying. Charles is 45 years old and has two brothers. Son of a nurturing mother and absent father, he displays no serious pathologies. Within the tour agency where he works, he obeys his superiors and wants to make a good impression on them. He appears to be motivated by external goals and responds well challenges. Though Charles has developed a high 
tolerance for uncertainty, his greed leads him to make bad business decisions. On one occasion, he lost almost 100,000 dollars. Charles has been in positions privilege within the organization; he even served as a chief executive officer (CEO) for two years. He never entered the university. During childhood, he lived in the same neighborhood in a loving home. Consequently, his network of friends and neighbors is very strong. Life slapped in the face when his girl friend succumbed to cancer at the age of 20. Charles never recovered from this traumatic event, and he became alcoholic for a while. Charles has a phobia of flying. This affected his performance as a CEO, because many overseas journeys had to be cancelled. His worries are not related to the security of his family when is on vacations or holidays if the means of transport would be a bus or a car. His fears decline if he flies accompanied by another person. The frustration, according to Charles' account, comes from the fact that his brothers love to travels on holidays no matter the kind of transport. Despite his success in business, various crises with his wife led him to think that there was something wrong with his personality. He wanted a recovery through psychological therapy, but at present, he has failed in all attempts.

In contrast to Charles, John has a bachelor's degree and doctorate in tourism. Considered as very intelligent by his colleagues and as having the ability to solve his own issues, John is reluctant to accept the viewpoint of his bosses. During his career, he showed fewer problems in working with groups. Married with three children, he loves his wife and never had a partnership conflict. Unlike Charles, John has lived in various neighborhoods and created a solid network of friends. He is not praised or assessed positively by his superiors in the tourism agency where he works. Jonny has developed a high tolerance of uncertainty, but hates the administration's goals and objectives. He views the world as a dangerous place where one should be cautious in forming relationships. Positions of privilege and authority mean nothing to John, and neither the money nor career advancement are important to him. Unlike Charles, John hates to travel, no matter the distance, when his family remains at home. Experienced as separation anxiety rather than panic attacks of phobia, John suffers insomnia when gone for long periods far from home. Both he and Charles experienced a similar trauma: the loss of a loved one. John's father died in a domestic accident in the house when he was 20 years old. This traumatic event led him to take diverse drugs until 2009 when he ended a successful recovery process for drug abusers. Whereas for Charles travel by air is impossible, John does not feel the same. He is reluctant to travel alone or without his family regardless of the mode of transportation. When planning a vacation, John worries about the safety of his family, but this sentiment does not detract from the enjoyment of leisure travels. Both John and Charles have experienced a failed mourning process over the loss of a love-object, but their responses differ. While Charles fears for himself, John worries about others.

In the third case, Maria (35 years old) differs from Charles and John. She is a good employee in a leading tourist agency. As a brilliant student of economic sciences, her career was interrupted when she married. Maria, like Charles, had a nurturing mother. This type of maternal relationship stimulated her love for travel. One of her favorite activities in childhood was to go to the Buenos Aires domestic airport to see the airplanes take off where she was accompanied by her father. Despite her experience in planning travels for others, she has few experiences in visiting other cities or destinations. She has not traveled much in her life. Maria has developed a low tolerance for uncertainty and frustration. She started various psychological therapies to resolve the problem but without any result. In contrast to Charles, Maria does not consider flying a dangerous mode of transport, nor does she worry about her family when away from home. Though she aspires to positions of power and authority, she considers that the world is a beautiful place to live. Traumatic death has not determined her personality or character. 


\section{Conclusion}

Persons adapt to their environment in diverse ways. Depending on how these adaptations evolve, diverse models of behavior are moulded. We have collected three biographies which speak of the inner life and the corresponding expectations about travel. Variables such as profession, education, age, gender, or residency have no direct correlation with fear of travel. One of the primary conclusions we found is that profession is not a catalyst for risk. Tour operators who are familiar with the organization of travel may experience fear at the time they have to move. Although as we have discussed, this sentiment varies from panic to extreme worries, it is important not to lose the sight that the tolerance of uncertainty does not explain the issue. As the theory of attachment formulated by Bolwby put it, death or the loss of a love-object as well as the way mourning is resolved seem to show a strong correlation with risk perception. Maria has no fear of traveling since she has not experienced the trauma of relative's death. The phobia of Charles and the separation anxiety of John are determined by early traumatic events. An interesting line of risk research is the connection between fear of traveling and trauma. In a way, impossible to precise for us now, the fear of traveling would work as a defense mechanism connected to the mourning process. Overly burdensome work and the achievement of goals seem not to be important factors explaining the fear of traveling.

\section{References}

Bowlby, J. (1960). Grief and mourning in infancy and early childhood. In The psychoanalytic study of the child (pp. 9-52). New York, N.Y.: International University Press.

Hall, M., Timothy, D., \& Duval, T. (2003). Security and tourism: Towards a new understanding? In M. Hall, D. Timothy, \& T. Duval (Eds.), Safety and security in tourism: Relationships, management, and marketing (pp. 1-18). New York, N.Y.: Haworth Hospitality Press.

Hoxter, A. L., \& Lester, D. (1988). Tourist behavior and personality. Personality and Individual Differences, 9(1), 177-178.

Korstanje, M. E. (2011a). The fear of traveling: A new perspective for tourism and hospitality. Anatolia, 22(2), 222-233.

Korstanje, M. E. (2011b). Why risk why now? Conceptual problems around the risk perception in tourism industry. Revista Brasileira de Pesquisa em Turismo, 5(1), 4-22.

Kozak, M., Crotts, J. C., \& Law, R. (2007). The impact of the perception of risk on international travellers. International Journal of Tourism Research, 9(4), 233-242.

Larsen, S., Bruna, W., \& Øgaardb, T. (2009). What tourists worry about: Construction of a scale measuring tourist worries. Tourism Management, 30(2), 260-265.

McCartney, G. (2008). Does one culture all think the same? An investigation of destination image perceptions from several origins. Tourism Review, 63(4), 13-26.

Plog, S. (1973). Why destination areas rise and fall in popularity? The Cornell Hotel and Restaurant Administration Quarterly, 13(3), 13-16.

Plog, S. (1991). Leisure travel: Making it a growth market again. New York, N.Y.: John Wiley \& Sons.

Reisinger, Y., \& Mavondo, F. (2005). Travel anxiety and intentions to travel internationally: Implications of travel risk perception. Journal of Travel Research, 43(3), 212-225.

Roehl, W. S., \& Fesenmaier, D. R. (1992). Risk perceptions and pleasure travel: An exploratory analysis. Journal of Travel Research, 30(4), 17-26. 